\title{
Axon Regeneration Can Facilitate or Suppress Hindlimb Function after Olfactory Ensheathing Glia Transplantation
}

\author{
Aya Takeoka, ${ }^{1}$ Devin L. Jindrich, ${ }^{1,3}$ Cintia Muñoz-Quiles, ${ }^{4}$ Hui Zhong, ${ }^{1}$ Rubia van den Brand, ${ }^{1}$ Daniel L. Pham, ${ }^{1}$ \\ Matthias D. Ziegler, ${ }^{1}$ Almudena Ramón-Cueto, ${ }^{5}$ Roland R. Roy, ${ }^{1,2}$ V. Reggie Edgerton, ${ }^{1,2}$ and Patricia E. Phelps ${ }^{1,2}$ \\ ${ }^{1}$ Department of Integrative Biology and Physiology and ${ }^{2}$ Brain Research Institute, UCLA, Los Angeles, California 90095, ${ }^{3}$ Department of Kinesiology, \\ Arizona State University, Tempe, Arizona 85287, ${ }^{4}$ Fundación Investigación en Regeneración del Sistema Nervioso, 46019 Valencia, Spain, and ${ }^{5}$ Instituto de \\ Biomedicina de Valencia, Consejo Superior de Investigaciones Científicas, 46010 Valencia, Spain
}

Reports based primarily on anatomical evidence suggest that olfactory ensheathing glia (OEG) transplantation promotes axon regeneration across a complete spinal cord transection in adult rats. Based on functional, electrophysiological, and anatomical assessments, we found that $\mathrm{OEG}$ promoted axon regeneration across a complete spinal cord transection and that this regeneration altered motor responses over time. At 7 months after transection, 70\% of OEG-treated rats showed motor-evoked potentials in hindlimb muscles after transcranial electric stimulation. Furthermore, a complete spinal cord retransection performed 8 months after injury demonstrated that this axon regeneration suppressed locomotor performance and decreased the hypersensitive hindlimb withdrawal response to mechanical stimulation. OEG transplantation alone promoted reorganization of lumbosacral locomotor networks and, when combined with long-term training, enhanced some stepping measures. These novel findings demonstrate that OEG promote regeneration of mature axons across a complete transection and reorganization of spinal circuitry, both of which contribute to sensorimotor function.

\section{Introduction}

Adult rodent spinal cords retain an inherent plasticity to reorganize descending connections that directly influence motor output after incomplete injuries (Bareyre et al., 2004; Courtine et al., 2008). After a complete spinal cord transection, however, achieving axon regeneration across the lesion that contributes to functional recovery remains a difficult challenge. Olfactory ensheathing glia (OEG) transplantation reportedly promotes tissue sparing, axon remyelination, and improvements in motor performance in incomplete and complete adult spinal cord injury (SCI) models (Imaizumi et al., 1998; Ramón-Cueto et al., 2000; García-Alías et al., 2003; Li et al., 2003; Fouad et al., 2005; Li et al., 2007; Kubasak et al., 2008; Muñoz-Quiles et al., 2009). However, the results of SCI studies involving OEG transplantation vary substantially depending on the injury model, the duration of the study, and the source, age, and methods used to prepare and transplant the OEG (Franssen et al., 2007). Promising transplantation candidates that promote axon regeneration are purified cultures of olfactory bulb-derived, p75-nerve growth factor receptor (NGFR)-positive OEG (Ramón-Cueto et al., 2000) be-

\footnotetext{
Received Sept. 22, 2010; revised Nov. 7, 2010; accepted Dec. 22, 2010.

This work was supported by National Institute of Neurological Disorders and Stroke Grants R21NS42000-01 and R01NS54159.

We thank Dr. J. Gornbein for assistance in the statistical analyses, Dr. R. Ichiyama and S. Zdunowski for expert advice in behavioral data collection and analyses, Dr. G. Lawson and M. Herrera for the aid in postsurgical animal care, Drs. Ava Udvadia and Pate Skene for advice on GAP-43 experiments, and Allen Cheng, Alisha Aiello, Kimberly McFarland, Frank Lee, and numerous University of California, Los Angeles undergraduate students for assistance with animal care and preparation of data for analyses.

Correspondence should be addressed to Dr. Patricia E. Phelps, Department of Integrative Biology and Physiology, UCLA, Box 951606, Los Angeles, CA 90095-1606. E-mail: pphelps@physci.ucla.edu.

DOI:10.1523/JNEUROSCI.4967-10.2011

Copyright $\odot 2011$ the authors $\quad 0270-6474 / 11 / 314298-13 \$ 15.00 / 0$
}

cause these cells intermingle with astrocytes and migrate well within the reactive astrocytic environment after injury (Lakatos et al., 2000, 2003).

OEG transplantation combined with task-specific training improves the motor function of adult rats with a complete spinal cord transection (i.e., spinal rats) (Ramón-Cueto et al., 2000; Kubasak et al., 2008; Muñoz-Quiles et al., 2009), but we know little about how this treatment promotes functional recovery. The spinal cord alone is capable of inducing locomotor activity without supraspinal innervation and can be trained to enhance the efficacy of locomotion (Edgerton et al., 2004). For example, long-term step training promotes reorganization of the lumbosacral locomotor circuitry in adult spinal cats by downregulating inhibitory neurotransmitters associated with interneurons and somatic motor neurons (Edgerton et al., 1997; de Leon et al., 1999; Tillakaratne et al., 2000, 2002; Rossignol et al., 2001; Côté and Gossard, 2003) and by modifying motor neuron excitability in response to hindlimb loading and sensory stimulation (Côté et al., 2003). Combined with pharmacological or epidural electrical stimulation, long-term step training also increases the efficacy of specific sensorimotor connections and activates specific neurons during locomotion (Ichiyama et al., 2008; Courtine et al., 2009).

We hypothesized that OEG transplantation combined with long-term step training promotes both axon regeneration across the transection and/or reorganization of the lumbosacral locomotor circuitry in adult spinal rats. We then asked whether both regeneration and reorganization attributed to the treatments can influence functional outcomes. To test this, we used sensorimotor and electrophysiological assessments over 8 months and performed a complete retransection rostral to the original transection 8 months after the initial lesion. OEG transplantation 
promoted functional axon regeneration across the complete lesion, and, when combined with long-term step training, it facilitated reorganization of spinal locomotor networks. Moreover, some of the changes in motor function attributed to OEG transplantation and step training point to facilitation, whereas others result in suppression of sensorimotor function.

\section{Materials and Methods}

\section{OEG culture and transplantation}

All procedures followed the National Institutes of Health guidelines and were approved by the Chancellor's Animal Research Committee at UCLA. Methods for OEG culture were adopted from those of Ramón-Cueto et al. (2000) and Muñoz-Quiles et al. (2009). OEG were dissected from the outer two olfactory bulb layers of two 8- to 10-week-old male Wistar Hannover rats (Charles River Laboratories) for transplantation into one spinal rat. Primary cultures were immunopurified against p75-NGFR antibody (1:5) (Chandler et al., 1984) at $7-8 \mathrm{~d}$ and harvested for transplantation at $14 \mathrm{~d}$. Cultures $(n=10)$ were $95 \pm 1 \%$ p 75 -NGFR-positive and expressed S100 and GFAP.

Forty-one female Wistar Hannover rats, 10-12 weeks old, were anesthetized with $2-2.5 \%$ isoflurane. The spinal cord was completely transected at approximately $\mathrm{T} 9$, leaving the ventral and lateral dura intact. Injections of DMEM alone or with OEG (200,000 per stump) were injected $\sim 1 \mathrm{~mm}$ from the transection site at the midline (coordinates from the dorsal surface: $1.75,1.25,1$, and $0.5 \mu \mathrm{m}$ ) into both the rostral and caudal spinal cord stumps. After transplantation, the spine was stabilized with a stainless steel bar $(3.2 \mathrm{~cm}$ in length and $0.1 \mathrm{~cm}$ in diameter) attached to the T7 and T13 vertebral processes.

\section{Step training and behavioral analyses}

Two weeks after injury, the rats began manual step training on a treadmill for $20 \mathrm{~min} / \mathrm{d}, 5 \mathrm{~d} /$ week for 7.5 months as described by Kubasak et al. (2008). Stepping ability was evaluated before transection, monthly between 1 and 7 months after transection, and after spinal cord retransection at 8 months at treadmill speeds of $10,13.5$, and $17.5 \mathrm{~cm} / \mathrm{s}$ and with a body weight support of $85 \%$ (i.e., the hindlimbs supported $15 \%$ body weight). Recording of treadmill stepping was conducted as described by Kubasak et al. (2008). Each trial consisted of 90 s of stepping. The highest number of plantar steps at three treadmill speeds was sampled for each rat. At 5 months after transection, spinal rats were injected with quipazine $\left(0.3 \mathrm{mg} / \mathrm{kg}\right.$, i.p.) (Ichiyama et al., 2005), a $5-\mathrm{HT}_{2 \mathrm{~A}}$ receptor agonist, and stepping ability was tested 15 min later.

We used principal components analysis (PCA) to measure the consistency of the toe trajectories (Fong et al., 2005; Cai et al., 2006). Briefly, stride transitions were identified visually, kinematics trajectories of toe markers were resampled every $0.1 \mathrm{~s}$, and corresponding points across all measured steps were averaged. The first principal component, similar to an average that explains the greatest amount of variance among trajectories, was calculated and the variance accounted for by the first component was calculated as a "score." A larger PCA score (i.e., closer to 100\%) represents more consistent stepping. The best PCA score (percentage) from three treadmill speeds was sampled for each rat that performed three or more alternating steps. A PCA score of $45 \%$, the lowest PCA percentage measurable as defined by Cai et al. (2006), was assigned for spinal rats that performed two or fewer alternating steps. We also measured mean stance length, step height, and trajectory length to characterize the step patterns during treadmill testing.

Weight-support testing. Rats were supported using a harness connected to an automated body weight-support system (Robomedica) that lowered $10 \%$ of the rat's body weight every $10 \mathrm{~s}$ until the rat collapsed. The percentage body weight support at collapse was determined by an observer blind to the experimental status of the rat. Because ankle joint angles are good indicators of weight-support ability (Timoszyk et al., 2002), data from rats that collapsed forward were used to calculate the joint angle as described previously (Ichiyama et al., 2009). Ankle angle analyses were performed using the Simi threedimensional motion. von Frey test. An experimenter blind to the treatment status of the spinal rats conducted the von Frey up-down test (Chaplan et al., 1994) on both hindpaws at 1, 3, 5, and 7 months after transection and $5 \mathrm{~d}$ after spinal cord retransection to determine any injury-induced changes in the withdrawal threshold. A series of nine hairs (3.61-5.46 g, starting with the $4.56 \mathrm{~g}$; North Coast Medical) were used to elicit the hindpaw withdrawal response to determine the $50 \%$ withdrawal threshold (grams).

\section{Electrophysiological assessment of hindlimb motor-evoked potentials}

We performed transcranial electric stimulation at 1, 4, and 7 months after transection of all spinal rats and immediately after and 3 and $5 \mathrm{~d}$ after a retransection on 17 rats. Stimulation of four intact rats also was studied before and after acute transection. Rats were anesthetized lightly with $0.7-1 \%$ isoflurane and received stimulation on the primary motor cortex (approximately bregma -3.5 to $+2 \mathrm{~mm}$ ) using a method modified from López-Vales et al. (2006) and on the brainstem (approximately bregma -6 to $-10 \mathrm{~mm}$ ). Motor-evoked potentials (MEPs) were elicited by a series of single-pulse stimulations [ $0.1 \mathrm{~ms}$ duration, from 40 to 200 $\mathrm{mA}$ in $40 \mathrm{~mA}$ increments, 30 times/intensity applied at $30 \mathrm{~s}$ intervals; constant-current stimulator model DS7AH (Digitimer)]. MEPs were recorded bilaterally from the tibialis anterior (TA) and medial gastrocnemius (MG) muscles with subcutaneously inserted needle electrodes [needle: 30 gauge (BD Biosciences); wire: $50 \mu \mathrm{m}$ in diameter (California Fine Wire) ]. All MEPs were amplified (1000X) and filtered (10-10,000 $\mathrm{Hz}$ ). Each MEP was defined as a sharp peak with a latency longer than 8 $\mathrm{ms}$ and an amplitude larger than $0.05 \mathrm{mV}$. Electrical stimulation with high currents as used in this study can potentially introduce artifacts in MEP recordings as a result of volume conduction, stimulation of axial spinal musculature, and/or the activation of cutaneous trunci pathways (Gruner et al., 1993). Direct stimulation artifacts were of very short duration (i.e., $<1 \mathrm{~ms}$ ) and were observed in both media and OEG animals. Although we cannot exclude the possibility of extraspinal stimulation artifacts (e.g., via cutaneous trunci pathways), we consider it unlikely that such a reflex would only occur in OEG rats and would be eliminated by retransection.

\section{Morphological analyses}

Retrograde tracer injections and analyses. Twenty-two chronic spinal rats (media-untrained, $n=5$; media-trained, $n=7$; OEG-untrained, $n=5$; OEG-trained, $n=5$ ) were injected with horseradish peroxidase conjugated with wheat germ agglutinin (WGA-HRP) 8 months after transection. Additional controls included three intact and three media-injected spinal rats maintained 1 month after transection. Rats were anesthetized with $2 \%$ isoflurane, and a $0.65 \mu \mathrm{l}$ mixture of $5 \%$ WGA (Sigma) and $25 \%$ HRP (Sigma) was injected $5 \mathrm{~mm}$ caudal to the transection in 13 locations (coordinates expressed in mm: midline, 1.8, 1.4, 1.0, 0.8, and 0.4; at 1.2 $\mathrm{mm}$ to the right or left of the midline, 1.6, 1.2, 0.8, and 0.4) as reported previously (Ramón-Cueto et al., 1998; Muñoz-Quiles et al., 2009). After $72 \mathrm{~h}$, the rats were perfused for tissue analyses.

We sectioned the primary motor cortex and brainstem and mounted every third section (40 $\mu \mathrm{m}$ thick) on slides for WGA immunohistochemistry. Additionally, every eighth spinal cord section ( $25 \mu \mathrm{m}$ thick) from the cervical enlargement and the transection site of all WGA-HRPinjected spinal rats was processed for WGA immunoreactivity to detect long propriospinal neurons and to ensure that no tracer leaked into the lesion core and rostral stump, respectively. None of the rats evaluated for retrograde tracing data had WGA-HRP leakage into the lesion core or rostral stump (supplemental Fig. 1C, available at www.jneurosci.org as supplemental material). We used an imaging system (Simple PCI software; Compix Imaging Systems, Hamamatsu Corporation) to measure the optical density of WGA immunoreactivity in brainstem and spinal cord neurons. The maximum background level of $\sim 20$ large neurons outside the regions of interest, i.e., neurons that do not project to the spinal cord, were measured first to determine the maximal background level of each section. Cells within the nuclei of interest were detected only if their optical densities were $5 \%$ or greater than the maximal background level. Optical densitometry measurements were performed on every third section (120 $\mu \mathrm{m}$ apart) throughout the red and vestibular nuclei 
and the locus coeruleus and every 12th section (480 $\mu \mathrm{m}$ apart) throughout the reticular formation and raphe nucleus. All measurements were performed blind to the transplantation or training status of the rats.

Tissue preparation. Rats were anesthetized deeply with ketamine $(100 \mathrm{mg} / \mathrm{kg}$, i.p. $)$ and $x y-$ lazine $(5 \mathrm{mg} / \mathrm{kg}$, i.p.), perfused with $4 \%$ paraformaldehyde, and postfixed at $4^{\circ} \mathrm{C}$ for $4 \mathrm{~h}$. Spinal cords, brains, and brainstems were dissected and cryoprotected.

Antibodies. Monoclonal antibodies used included the following: anti-GFAP (1:1000; BD Pharmingen), anti-Neuronal-specific Nuclear protein (NeuN) (1:100), and anti-GAP43 (1: 10,000; Millipore Corporation). Polyclonal antibodies used included the following: goat antiWGA (1:2000; Vector Laboratories), goat anti5-HT (1:20,000; ImmunoStar), and rabbit anti-GFAP (1:30,000; Dako).

Immunohistochemistry and lesion site analyses. We sectioned the transection site in the sagittal plane $(25 \mu \mathrm{m})$ and mounted the sections on a series of 16 slides such that every 16th section was mounted on a slide. All immunohistochemistry procedures with diaminobenzidine (DAB), followed the monoclonal, polyclonal, or double immunolabeling protocols described previously (Takeoka et al., 2009, 2010). For immunofluorescence of GFAP and NeuN, we omitted the presoak and Triton X-100 steps. Species appropriate Alexa Fluor 488 and 584 (1:200; Invitrogen) were used for localization.

Quantification of 5-HT axons and GAP43 somata. 5-HT axons were quantified as reported by Takeoka et al. (2009). GAP43-positive somata present in the lower thoracic cord caudal to the original lesion were quantified in every eighth section of the caudal stump and normalized based on tissue volume.

Volume of the lesion core and associated cavities. Approximately $85 \%$ of the lesion site was GFAP labeled to delineate the lesion core and to anatomically confirm that all transections were complete. In all rats, the GFAP-negative core always separated the GFAP-positive rostral and caudal stumps as reported in our previous study (Kubasak et al., 2008). The volume of the lesion core and the associated cavities was quantified as reported (Kubasak et al., 2008). We outlined the GFAP-negative transection site and the nearby cavities of all rats injected with the retrograde tracer $(n=22$ rats). The GFAP-positive area was subtracted from the total section area in every eighth section (25 $\mu \mathrm{m}$ thick) and normalized based on tissue volume. We focused on differences between the media and OEG groups because there were no training effects.

Length of the non-neuronal tissue and lesion core. We double labeled every eighth section for GFAP and NeuN to estimate the extent of lesion-induced neuronal degeneration in spinal cord tissue rostral and caudal to the injury site. We measured (1) the shortest distance between NeuN-labeled neurons and the GFAP-positive border adjacent to the GFAP-negative lesion core in both the rostral and caudal stumps and (2) the total lengths of the non-neuronal region and the lesion core.
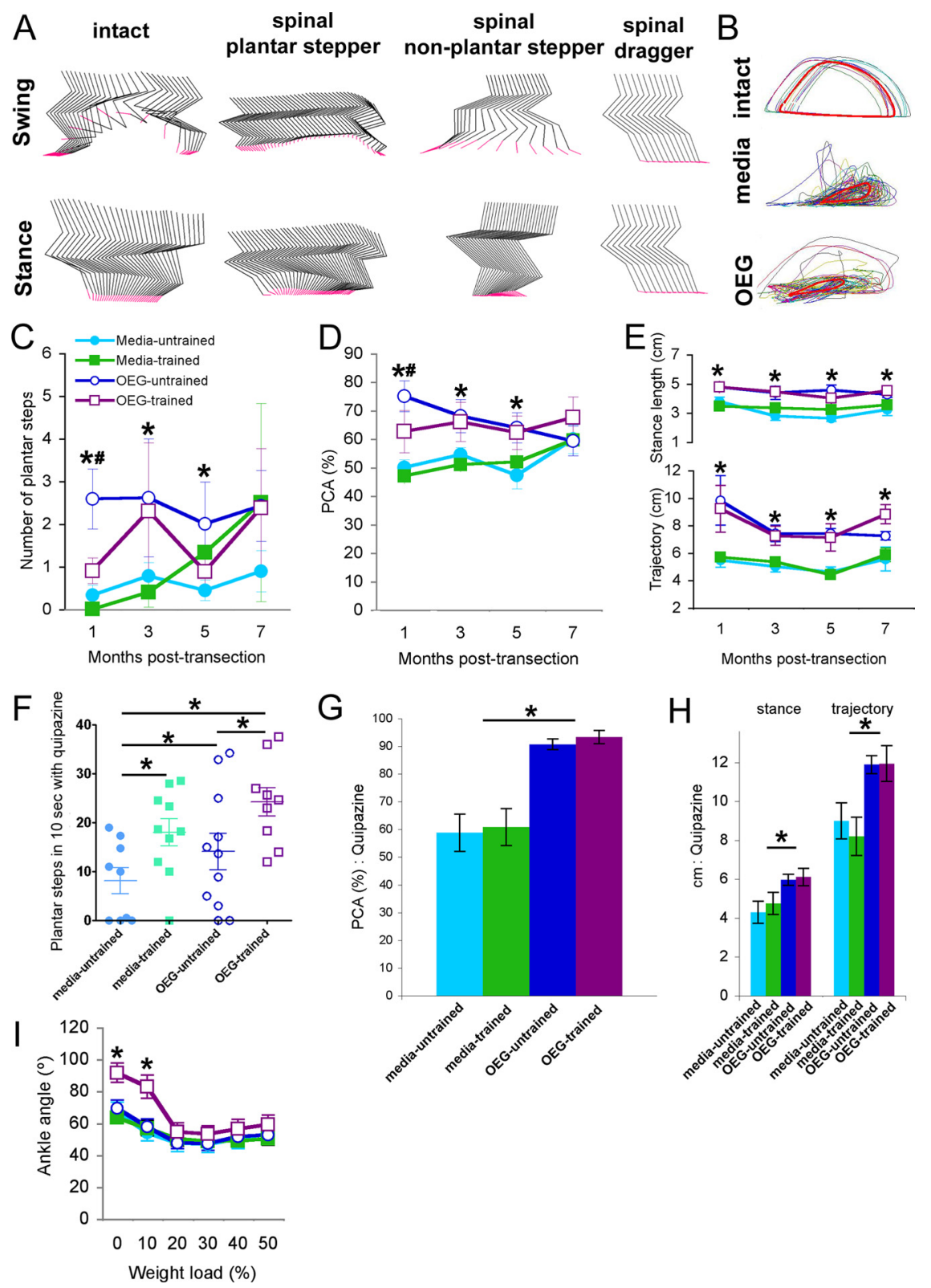

Figure 1. OEG transplantation and long-term step training influence locomotor function in spinal rats. $\boldsymbol{A}$, Ankle flexion and extension (highlighted in pink) are critical for successful plantar stepping, which is rarely achieved by adult spinal rats. Stepping is oriented toward the left (stick representation is sampled every $0.2 \mathrm{~s}$ ). Step heights of spinal plantar steppers are usually not as high as those of intact rats. Foot (pink) is placed vertical to the treadmill during successful plantar steps performed by intact rats that step on their footpads, whereas the foot of nonplantar steppers and draggers is parallel to the treadmill. $\boldsymbol{B}$, Step trajectories of intact rats are consistent, whereas those of spinal rats are erratic. Each colored line indicates a single step, and the thick red line represents the average trajectory. Step height is lower and stance and step trajectory lengths are shorter in media- and OEG-injected spinal rats than intact rats. C, OEG-untrained rats generated more plantar steps than media-untrained rats at 1,3 , and 5 months $\left({ }^{*} p<0.05\right)$ and more plantar steps than OEG-trained rats at 1 month ( $\left.{ }^{\#} p<0.05\right)$. D, PCA showed that both OEG groups produced more consistent step trajectories than both media groups at 1,3 , and 5 months $\left({ }^{*} p<0.05\right)$. 0EG-untrained rats scored higher than OEG-trained rats at 1 month ( $\left.{ }^{\#} p<0.05\right)$. E, OEG and media groups differed in their stance and trajectory lengths at all time points $\left({ }^{*} p<0.05\right)$. $\boldsymbol{F}$, Step training improved the number of plantar steps taken in 10 s in response to $5-\mathrm{HT}_{2 \mathrm{~A}}$ receptor activation $\left({ }^{*} p<\right.$ 0.05; see supplemental videos, available at www.jneurosci.org as supplemental material). Data for individual rats are represented as a circle or square. $\mathbf{G}, \boldsymbol{H}, 0$ EG injection but not step training enhanced step consistency $(\boldsymbol{G})$ and stance and trajectory lengths $(\boldsymbol{H})$ after quipazine injection $\left({ }^{*} p<0.05\right)$. I, OEG-trained rats exhibit better ankle extension than all other rats when the hindlimbs support up to $10 \%$ of their body weight at 7 months after transection $\left({ }^{*} p<0.05\right)$. Data are mean \pm SEM.

Statistical analyses. The nonparametric Mann-Whitney test was used for the von Frey analyses. All other statistical comparisons were conducted with nonparametric resampling analyses to compare group mean differences and minimize the assumptions on the underlying data distribution (Efron and Tibshirani, 1991). 
A

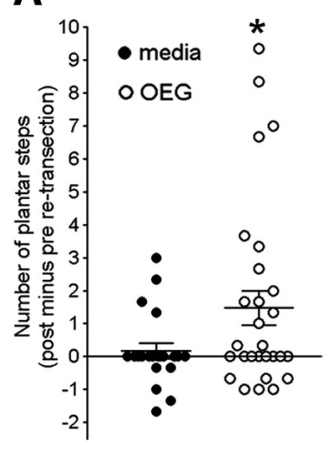

B

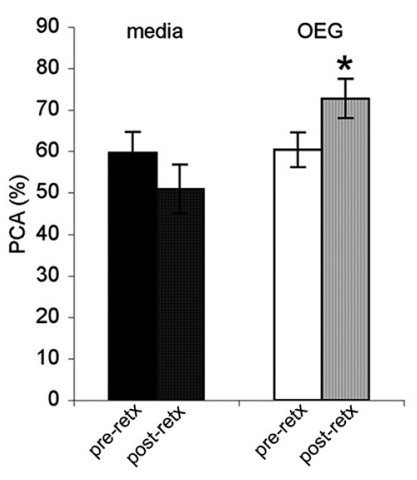

C
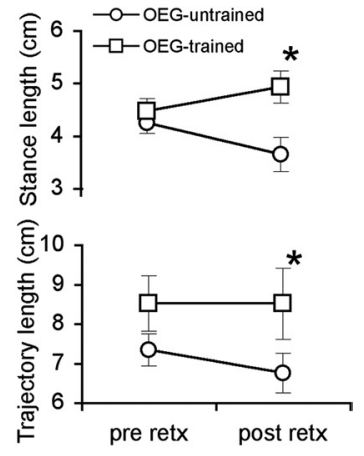

D

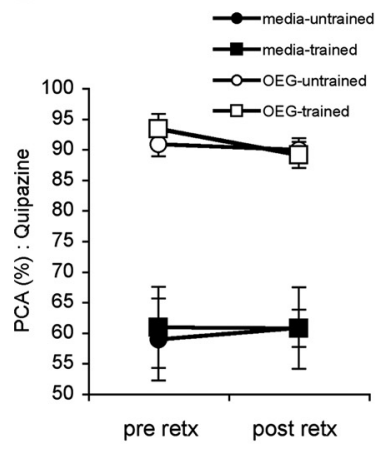

E

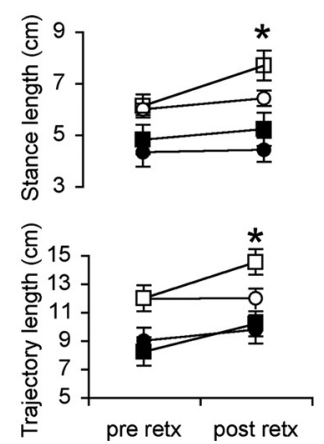

$\mathbf{F}$

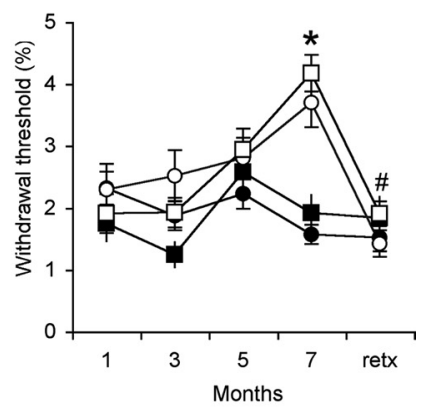

Figure 2. Retransection experiments demonstrate that functional regeneration contributes to motor recovery. $\boldsymbol{A}, 0 \mathrm{EG}$-injected rats generate more plantar steps after than before retransection (after minus before retransection; ${ }^{*} p=0.01$ ), whereas mediainjected rats do not change ( $p=0.34$ ). Data for individual rats are represented as a circle. $\boldsymbol{B}, 0 \mathrm{EG}$-injected rats have more consistent step trajectories after than before retransection $\left({ }^{*} p<0.05\right)$. Media groups did not differ. $\boldsymbol{C}$, After retransection, OEG-trained rats have longer stance and step trajectory lengths than $0 \mathrm{EG}$-untrained rats $\left({ }^{*} p<0.05\right)$. D, E, After quipazine injection, retransection did not alter the step consistency of any group $(\boldsymbol{D})$. Only the 0 EG-trained group had longer stance and step trajectory lengths after than before retransection $\left(\boldsymbol{E} ;{ }^{*} p<0.05\right)$. $\boldsymbol{F}$, Regardless of transplantation or training status, all spinal rats were hypersensitive to mechanical hindpaw stimulation between 1 and 5 months after transection. At 7 months, media groups remained hypersensitive, whereas $0 \mathrm{EG}$ groups became less sensitive, i.e., have a higher withdrawal threshold $\left({ }^{*} p<0.001\right)$. Spinal cord retransection (retx) reversed the improvement observed in OEG-injected rats ( ${ }^{*} p<0.001$ ) but had no effect on mediainjected rats $(p=0.65)$. Data are mean \pm SEM. OEG-untrained and -trained groups were combined in $\boldsymbol{A}$ and $\boldsymbol{B}$ because of a lack of a training effect.

\section{Results}

After a complete spinal cord transection at T9, spinal rats received injections of olfactory bulb-derived OEG suspended in media or media alone. Long-term step training of one half of the spinal rats started 2 weeks after transection and continued for 20 $\mathrm{min} / \mathrm{d}, 5 \mathrm{~d}$ /week for 7.5 months. The four experimental groups were as follows: media-untrained $(n=9)$, media-trained $(n=$ $10)$, OEG-untrained $(n=11)$, and OEG-trained $(n=9)$. Eight months after the initial transection, $50 \%$ of the spinal rats received a complete retransection rostral to the original lesion, and the remaining $50 \%$ were injected with a retrograde tracer.

\section{OEG transplantation improves hindlimb step performance}

Plantar foot placement during hindlimb stepping requires a series of joint movements, i.e., knee and ankle flexion during the swing phase and ankle extension during the stance phase, and is rarely achieved spontaneously by adult spinal rats (Fig. 1A) (Edgerton et al., 2004). Step trajectories of spinal rats measured by PCA are often erratic compared with those of intact rats (Fig. $1 B$ ). To determine whether OEG transplantation promotes hindlimb stepping ability in adult spinal rats, we first compared the number of plantar steps taken by media- and OEG-untrained spinal rats.

OEG-untrained rats generated significantly more plantar steps than mediauntrained rats at $1-5$ months after transection but not at later time points (Fig. 1C). Neither the media- nor the OEG-untrained rats improved their plantar stepping ability over time (Fig. 1C). Next we asked whether or not there was a training effect. The average number of plantar steps did not differ statistically between the media-untrained and -trained groups throughout the study (Fig. 1C). The OEG-untrained group consistently produced as many or more plantar steps than the OEG-trained group, with significant differences detected early in the study (Fig. 1C).

We used PCA to calculate the consistency of the step trajectories and also compared stance lengths, step heights, and trajectory lengths. PCA analysis assesses the ability to produce locomotor movement, i.e., hindlimb alternation with or without hindlimb plantar placement. The stepping pattern was more consistent, represented by higher PCA scores, for both OEG-untrained and -trained groups compared with media groups at 1, 3, and 5 but not at 7 months (Fig. 1D). The OEGuntrained rats had higher PCA scores than OEG-trained rats at 1 month. Both OEG groups demonstrated longer stance and trajectory lengths than media groups throughout the duration of the study (Fig. $1 E)$. Mean step height did not differ among groups at any time point, and there was no improvement in step consistency, step height, or stance and trajectory lengths over time in any group. Together, these results indicate that OEG transplantation alone can enhance stepping ability, and these improvements occurred early in the study with no change over time.

\section{OEG transplantation and step training improve plantar} stepping ability associated with $5-\mathrm{HT}_{2 \mathrm{~A}}$ receptor activation Administration of quipazine, a $5-\mathrm{HT}_{2 \mathrm{~A}}$ receptor agonist, can activate and modulate the lumbosacral locomotor networks in spinal rats (Gerasimenko et al., 2007; Ichiyama et al., 2008). We therefore gave a single injection of quipazine 5 months after transection to determine the extent to which OEG transplantation and/or step training affected the locomotor circuitry associated with $5-\mathrm{HT}_{2 \mathrm{~A}}$ receptors. The administration of quipazine dramatically improved the number of consecutive plantar steps, stepping consistency, step height, and stance and step trajectory lengths in all four treatment groups compared with their predrug performance (supplemental Videos 1-4, available at www. jneurosci.org as supplemental material). Although we did not detect a training effect on plantar stepping without quipazine, activation of the $5-\mathrm{HT}_{2 \mathrm{~A}}$ receptors by quipazine unmasked a refinement in plantar stepping ability in media- and OEG-trained spinal rats (Fig. $1 F, 17.5 \mathrm{~cm} / \mathrm{s}$ ). In addition, $5-\mathrm{HT}_{2 \mathrm{~A}}$ receptor activation resulted in a more consistent stepping pattern (Fig. 
$1 G)$ and stance and trajectory lengths were longer (Fig. $1 \mathrm{H}$ ) in the OEG compared with the media groups. These results indicate that long-term step training and OEG transplantation contributed to the reorganization of the lumbosacral locomotor networks modified by serotonergic (5-HT) receptor activation.

\section{Only OEG-trained rats show greater ankle extension during the stand test} The effects of OEG transplantation and training on weight-support ability were measured as a part of the evaluation of locomotor ability. Spinal rats increased the amount of self-weight support before collapse between 1 and 4 months regardless of treatment (10 $\pm 1 \%$ increase), but only the OEG-injected groups improved between 4 and 7 months after transection ( $6 \pm 1 \%$ increase). Step training did not further enhance standing ability in any group.

We then measured changes in ankle extension during standing as an evaluation of weight-support ability (Timoszyk et al., 2002). At 1 and 4 months after transection, the mean ankle angles did not differ across the treatment groups at any level of weight support $(p>0.05$ for all comparisons). At 7 months, however, OEG-trained rats demonstrated greater ankle extension at 0 and $10 \%$ body weight support compared with the other three groups (Fig. 1I). Beyond 10\%, there were no group differences. These results indicate that OEG transplantation and step training together, but not individually, improved ankle extension up to the $\sim 10 \%$ body weight load used during step training.

Plantar stepping ability improves after retransection only in OEG-injected rats To test whether axon regeneration contributes to locomotor activity, we compared the number of plantar steps generated by media or OEG rats before and after a complete retransection $0.5 \mathrm{~cm}$ rostral to the original lesion. We subtracted the number of plantar steps generated at 7 months from those produced after the retransection at 8 months; a positive number, therefore, indicates a better stepping performance after retransection. Because there was no training effect on the number of plantar steps taken after retransection, we combined mediauntrained and -trained, and OEGuntrained and -trained groups. Although the mean number of plantar steps for the media group did not change after retransection, the OEG group showed a considerable improvement (Fig. 2A). Remarkably, two OEG-injected spinal rats that never

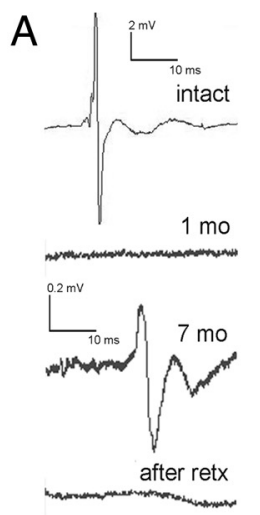

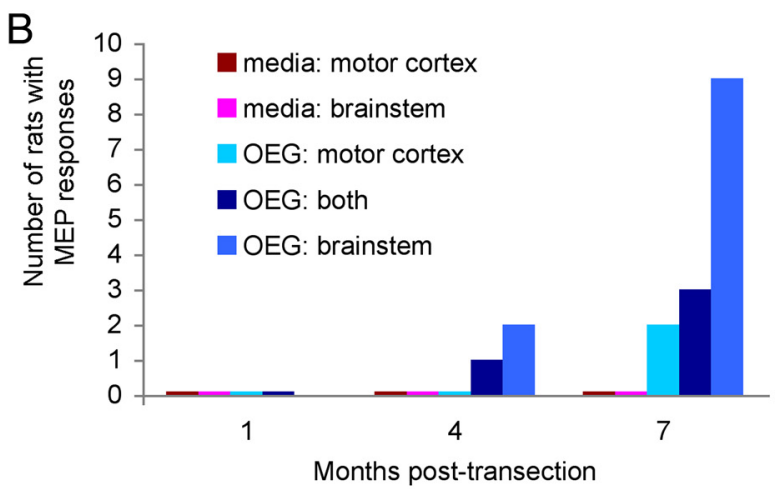
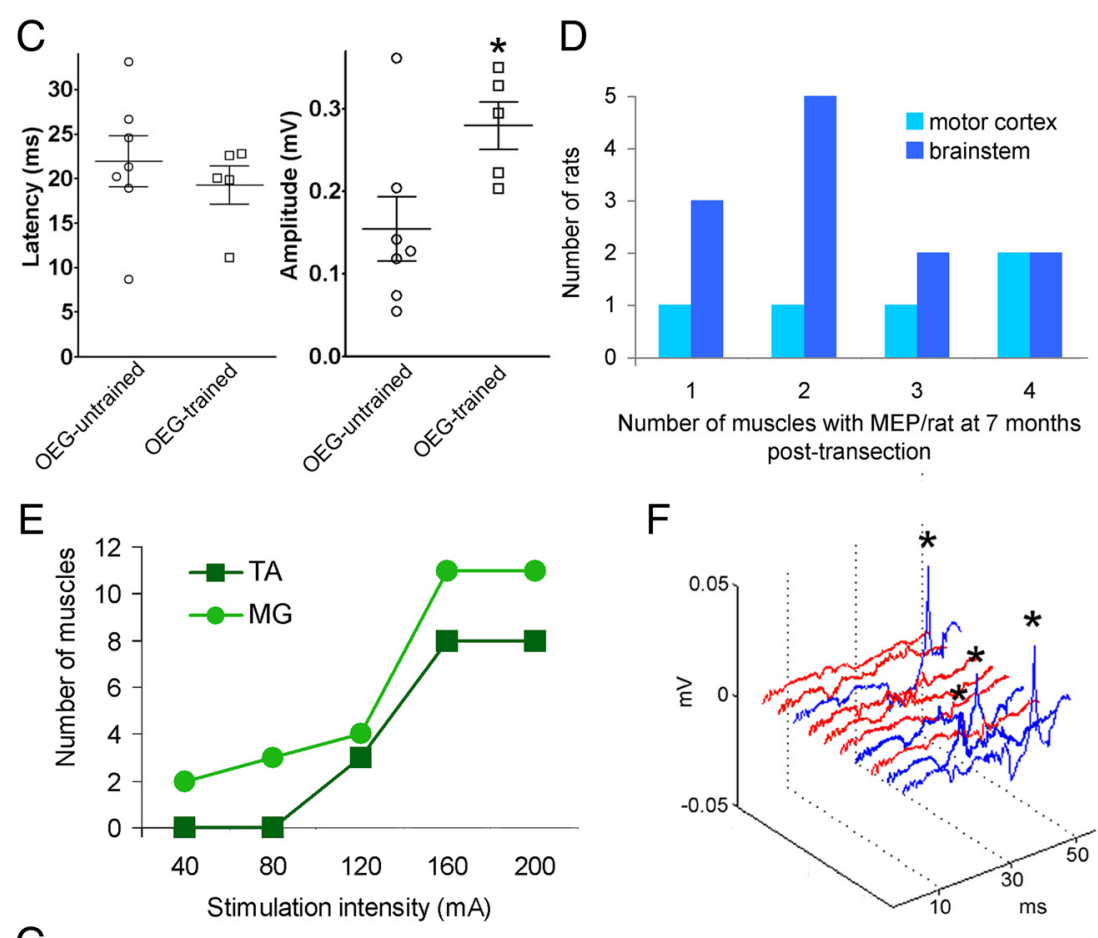

\begin{tabular}{|c|c|c|c|c|c|c|}
\hline \multirow{2}{*}{} & \multicolumn{2}{|c|}{ intact } & \multicolumn{2}{c|}{$4 \mathrm{mo}$} & \multicolumn{2}{c|}{$7 \mathrm{mo}$} \\
\cline { 2 - 6 } & latency & amplitude & latency & amplitude $^{*}$ & latency * $^{\text {*amplitude }}$ \\
\hline motor cortex & $8.30 \pm 0.61 \mathrm{~ms}$ & $2.53 \pm 0.26 \mathrm{mV}$ & $30.84 \pm 2.06 \mathrm{~ms}$ & $0.14 \pm 0.02 \mathrm{mV}$ & $22.26 \pm 1.58 \mathrm{~ms}$ & $0.18 \pm 0.19 \mathrm{mV}$ \\
\hline brainstem & $8.03 \pm 0.16 \mathrm{~ms}$ & $3.74 \pm 0.31 \mathrm{mV}$ & $27.02 \pm 2.45 \mathrm{~ms}$ & $0.17 \pm 0.01 \mathrm{mV}$ & $16.07 \pm 5.15 \mathrm{~ms}$ & $0.51 \pm 0.26 \mathrm{mV}$ \\
\hline
\end{tabular}

Figure 3. OEG promote functional reconnections of descending pathways across the transection. $A$, The top trace represents an MEP ( $\sim 8$ ms latency) from the MG of an intact rat in response to brainstem stimulation. The bottom three traces are recordings from the left MG of an OEG-injected rat. MEPs were not detected 1 month after transection. At 7 months, a typical MEP had a small amplitude $(\sim 0.25 \mathrm{mV}$ ) and long latency $(\sim 20 \mathrm{~ms})$. Retransection rostral to the initial transection site abolished the MEP signals (bottom trace, retx). $\boldsymbol{B}$, Only OEG-injected rats displayed MEPs at 4 and 7 months. Several OEG-injected spinal rats displayed MEPs to both cortical and brainstem stimulation at 4 and 7 months. $C$, The MEP amplitude in response to brainstem stimulation was larger in the OEG-trained than OEG-untrained group ( $\left.{ }^{*} p<0.05\right)$, but the latency did not differ. $\boldsymbol{D}$, When MEPs were detected in OEG-injected rats, $>50 \%$ exhibited MEP in multiple muscles at 7 months. $E$, More MG muscles responded to brainstem stimulation than TA muscles at 7 months after injury. Higher stimulation intensities induced more MEPs in both muscles. The total number of muscles across all OEG-injected rats is shown. $\boldsymbol{F}$, An OEG-treated rat with multiple MEPs with long latencies $\left(^{*}\right)$ in the right MG after 10 consecutive stimulations at $160 \mathrm{~mA}$. Responses occurred inconsistently (MEP in blue traces and no response in red traces) and varied in latency and amplitude. $\mathbf{G}$, Both the latency and amplitude of MEPs recorded from OEG rats are different from those from intact rats $\left({ }^{*} p<0.05\right)$. MEPs in response to cortical and brainstem stimulation are longer in latency and larger in amplitude at 7 than 4 months ( ${ }^{*} p<0.05$ ). No MEPs were detected in media-injected rats. OEG-untrained and -trained groups were combined in $\boldsymbol{B}, \boldsymbol{D}, \boldsymbol{E}$, and $\boldsymbol{G}$ due to the lack of a training effect.

stepped before retransection generated six to nine plantar steps after retransection. The number of plantar steps taken after retransection was significantly greater in OEG- than mediainjected rats (media, $0.9 \pm 0.2$; OEG, $1.7 \pm 0.4 ; p<0.05$ ). In 


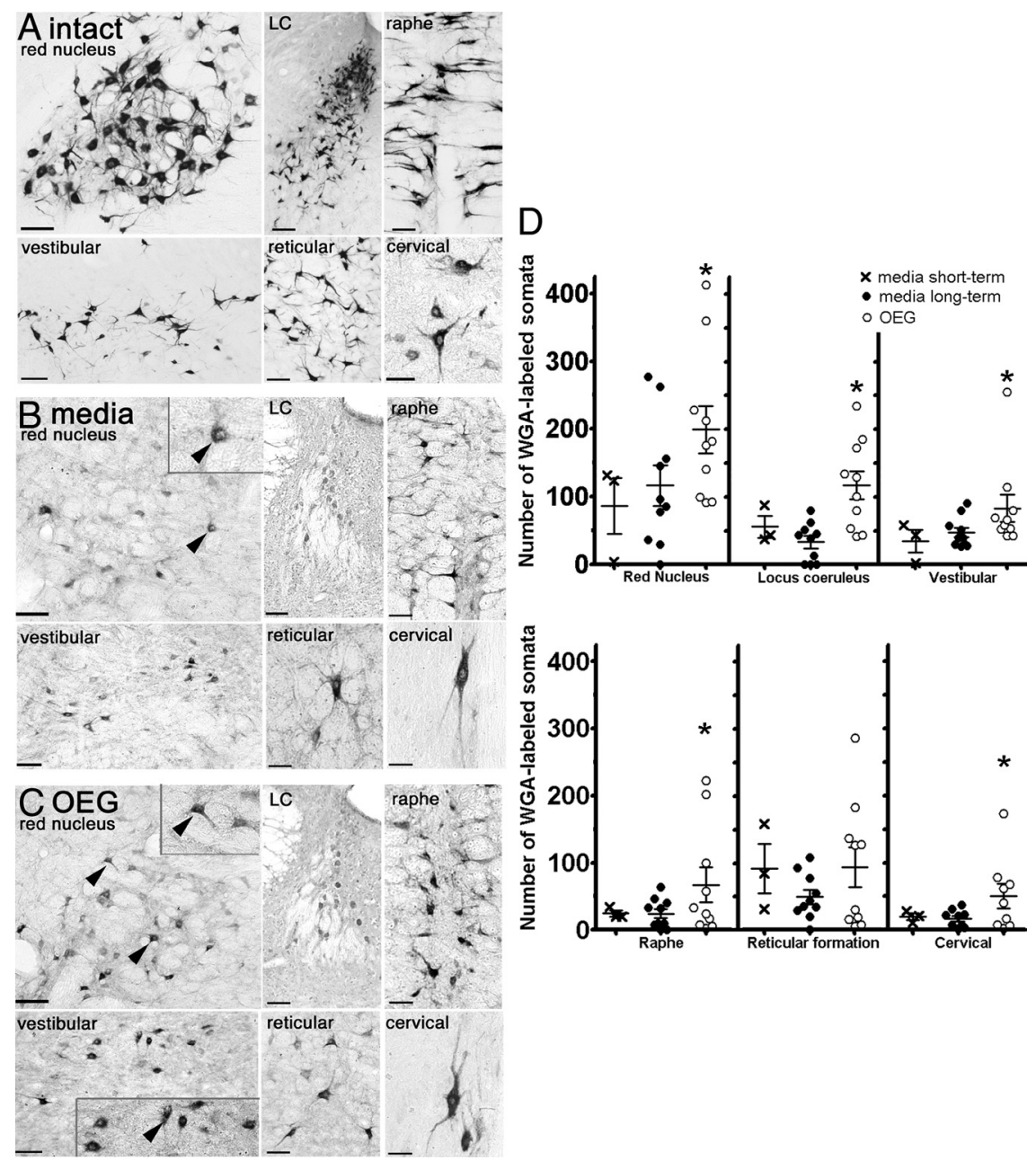

Figure 4. WGA-immunolabeled somata are present in coronal brainstem sections and parasagittal sections of the cervical enlargement of intact $(\boldsymbol{A})$, media-injected $(\boldsymbol{B})$, and OEG-injected $(\boldsymbol{C})$ rats. $\boldsymbol{A}$, WGA-HRP labels projection neurons in five brainstem nuclei and long propriospinal neurons in laminae VII-VIII of the cervical spinal cord in intact rats. $B, C$, Fewer WGA-positive somata were detected in media-injected $(\boldsymbol{B})$ and 0 EG-injected $(\boldsymbol{C})$ rats than in the same areas of intact rats $(\boldsymbol{A})$. Scale bars: red nucleus, locus ceruleus, and vestibular nucleus, $100 \mu \mathrm{m}$; raphe nucleus and reticular formation, $50 \mu \mathrm{m}$; cervical spinal cord, $25 \mu \mathrm{m}$. D, The number of WGA-labeled somata were greater in OEG-injected than in short- or long-term media groups in all areas $\left({ }^{*} p<0.05\right.$ for all comparisons) except the reticular formation. Short- and long-term media controls did not differ in brainstem nuclei or in the cervical spinal cord. WGA-positive somata in the reticular formation did not differ between any groups. Error bars are SEM.

ings imply that the improvement in stepping performance with quipazine reflects some intraspinal reorganization not directly dependent on axon regeneration.

\section{OEG transplantation decreases the withdrawal reflex threshold}

The hindlimb flexion response to mechanical stimulation primarily represents a spinally organized sensorimotor response (Zemlan et al., 1984). Because lesion-induced hyper-reflexia is commonly associated with SCI (Magladery et al., 1952; Reese et al., 2006), we used the von Frey test (Chaplan et al., 1994) to examine the effects of OEG transplantation and long-term step training on the hindlimb withdrawal response to mechanical stimulation. Adult intact rats had a withdrawal threshold of $7.9 \pm 1.0 \mathrm{~g}(n=$ 8). One month after transection, all four groups of spinal rats were hypersensitive to stimulation (Fig. $2 F$ ) (overall mean, $2.1 \pm 0.2 \mathrm{~g}$ ). Although we did not detect a training effect at any time point, the OEG groups were less sensitive to mechanical stimulation than the media groups at 7 months (Fig. $2 F$ ). We then compared the withdrawal threshold before and after retransection. Retransection did not alter this response in media-injected rats but abolished the improvement in OEG-injected rats. These findings indicate that functional connections across the transection mediated the reduced hypersensitivity observed in rats with OEG transplantation.

\section{OEG transplantation promotes axon regeneration across the transection: electrophysiological evidence}

We used transcranial electric stimulation to evaluate whether OEG promote func-

addition, OEG groups demonstrated more consistent step trajectories after retransection than before, whereas the media groups did not differ, as determined by PCA (Fig. $2 B$ ). There was no training effect on stepping consistency in either the media or OEG groups after retransection (data not shown). Stance and trajectory lengths were longer in OEG-trained than OEGuntrained rats after retransection, whereas no difference was observed between the media-trained and media-untrained rats (Fig. $2 C)$. The results from the retransection experiments suggest that OEG implantation promoted axon regeneration across the original transection site, and the reestablished connections predominantly acted to suppress locomotor performance.

After the combination of retransection and quipazine injection, stepping parameters were compared with those before retransection ( 5 months) (Fig. $1 F$ ). Retransection did not alter the number of plantar steps in any group (data not shown). Moreover, consistency of step trajectories (Fig. 2D) or step heights evaluated with PCA did not differ after retransection among groups. Only the OEG-trained rats improved their stance and trajectory lengths after retransection (Fig. 2E). These find- tional connectivity across the lesion site after a complete spinal cord transection. Because the stimulation intensity required to elicit MEPs depends on the type of anesthetic, level of anesthesia, location of stimulation and recordings, and diameter of stimulation/recording electrodes, we initially performed control experiments on intact rats. Stimulation of both the motor cortex and brainstem of intact rats $(n=4)$ consistently elicited MEP bilaterally in the MG and TA muscles that disappeared after acute spinal cord transection, indicating that MEPs detected in MG and TA are transmitted through the spinal cord. Additionally, MEPs had longer latencies and/or were eliminated by pharmacological blockage of excitatory neurotransmitters in intact controls (Protas et al., 2008), suggesting that evoked potentials with latencies longer than $1 \mathrm{~ms}$ are very likely attributable to neural transmission. Typical MEPs from intact rats were $2-10 \mathrm{mV}$ with a latency of $\sim 8 \mathrm{~ms}$ (Fig. $3 A, G$ ). With stronger stimulation intensities, MEP amplitudes increased, whereas the latencies were unaffected (data not shown).

The recordings at 1 month after lesion confirmed electrophysiologically that the spinal cord transections were complete 
Table 1. Quantification of WGA-labeled cell bodies from the retrograde tracing study

\begin{tabular}{lcccc}
\hline Treatment & Red nucleus* & Locus coeruleus* & $\begin{array}{l}\text { Vestibular } \\
\text { nucleus* }\end{array}$ & $\begin{array}{c}\text { Cervical } \\
\text { enlargement* }\end{array}$ \\
\hline Sham rats $(n=3)$ & $2253 \pm 509$ & $789 \pm 150$ & $972 \pm 266$ & $499 \pm 9$ \\
Short-term media-injected rats $(n=3)$ & $87 \pm 51$ & $56 \pm 20$ & $34 \pm 20$ & $25 \pm 6$ \\
Long-term media-injected rats $(n=10)$ & $116 \pm 30$ & $33 \pm 9$ & $47 \pm 7$ & $24 \pm 7$ \\
OEG-injected rats $(n=10)$ & $199 \pm 34$ & $117 \pm 21$ & $91 \pm 45 \pm 138$ & $20 \pm 5$ \\
\hline
\end{tabular}

More WGA-positive cell bodies were detected in OEG-injected than short- or long-term media-injected rats, i.e., controls. ${ }^{*} p<0.05$, statistical significance between both short- and long-term media-injected versus 0 EG-injected rats.

(Fig. 3A). No media-injected rats responded to stimulation at either site at any time point. Four months after transection, we detected MEPs with long latencies and small amplitudes in 15\% (motor cortex, $n=1$ of 22; brainstem, $n=3$ of 22) of OEGinjected rats (Fig. $3 B, G$ ). More OEG-injected rats exhibited MEPs, the mean latency was shorter, and the amplitude was larger at 7 than 4 months after transection (Fig. $3 B, G$ ). When combined, a total of $70 \%$ (motor cortex, 5 of 20; brainstem, 12 of 20) of the OEG-injected rats responded to cortical and/or brainstem stimulation at 7 months (Fig. 3B). Brainstem stimulation elicited relatively stronger MEPs, i.e., shorter latencies and larger amplitudes, than cortical stimulation (Fig. 3G). In contrast to intact rats, the MEP amplitudes recorded from OEG-injected rats did not increase consistently with increased stimulation intensity (data not shown). In addition, MEP latencies and amplitudes were longer and smaller, respectively, in OEG than intact rats (Fig. 3G). Interestingly, 15\% (3 of 20) of OEG-injected rats displayed MEPs with latencies indistinguishable from those in intact rats, i.e., $\sim 8 \mathrm{~ms}$, in response to either motor cortex or brainstem stimulation at 7 months after transection. Long-term step training did not influence MEP occurrence because 50\% (OEGuntrained, 7 of 14; OEG-trained, 7 of 14) of the rats with MEPs were in each OEG group. The mean MEP amplitude, however, was larger in the OEG-trained than -untrained group despite no differences in the mean latency between groups (Fig. $3 C$ ). Because fresh muscle weight of bilateral medial gastrocnemius, tibialis anterior, soleus, and extensor digitorum longus examined postmortem did not differ between OEG-untrained and trained groups (data not shown), the higher MEP amplitude in OEG-trained rats is likely attributable to changes in the spinal cord reorganization rather than increased muscle mass from training.

The number of muscles with MEPs in response to either cortical or brainstem stimulation varied in each rat at 7 months (Fig. $3 D)$. Seventy-percent (11 of 14) of OEG-injected spinal rats had responses in two or more muscles, and 21\% (3 of 14) of rats had responses in all four muscles tested. More MEPs were elicited in the MG than TA at all stimulation intensities in response to both brainstem and cortical stimulation (Fig. 3E). Although stimulation intensity did not correlate with MEP amplitude, more muscles were recruited with higher stimulation intensities, i.e., more TA and MG displayed MEPs at the higher stimulation intensities (Fig. 3E). Many of these muscles exhibited inconsistent responses to the same stimulation intensity, in that not all stimulation pulses in a series elicited an MEP (incidence of response varied from 10 to $100 \%$ ) and the stimulation intensity did not appear to influence the incidence of response (data not shown). Moreover, consecutive stimulations at a single intensity could elicit evoked potentials with different latencies and amplitudes in 30\% of the rats $(6$ of 14$)($ Fig. $3 F)$, a phenomenon not observed in intact rats. This variation suggests that different synaptic reconnections were activated in response to a specific stimulus and that the functional reconnections of descending pathways were not robust enough to respond to every stimulation.
Eight months after injury, we performed transcranial stimulation on 7 media-injected and 10 OEG-injected rats immediately before, immediately after, and 3 and $5 \mathrm{~d}$ after retransection to determine whether these MEP signals represent physiological reconnections across the original transection site. The MEPs were abolished after retransection in every rat with detectable evoked potentials before retransection (Fig. $3 A$, bottom trace, retx), providing additional evidence that OEG promoted electrophysiologically viable reconnections across the original lesion.

\section{OEG transplantation may promote axon regeneration across} the transection: anatomical evidence

Regeneration of descending brainstem and cervical spinal cord axons

To determine the extent of axon regeneration across the transection, we injected WGA-HRP into the lower thoracic cords of 3 intact and 22 spinal rats 8 months after transection (media-untrained; $n=5$, media-trained; $n=7$, OEG-untrained; $n=5$, OEG-trained; $n=5$ ). None of the spinal rats included in additional analyses had leakage of WGA-HRP into the lesion core or the rostral stump (supplemental Fig. 1C, available at www. jneurosci.org as supplemental material). In intact rats, we detected WGA-positive somata in the motor cortex (supplemental Fig. $1 A$, available at www.jneurosci.org as supplemental material), red nucleus, locus coeruleus, vestibular nucleus, reticular formation, raphe nucleus, and cervical enlargement (Fig. 4A). Based on an objective densitometry method, the number of WGA-positive somata in the brainstem and rostral spinal cord of both media and OEG groups was quantified without knowledge of the experimental status of each rat (Fig. $4 B, C$ ). Immunoreactive cells were considered as WGA-positive only when their optical density was at least $5 \%$ greater than the maximum background level determined in each section (supplemental Fig. $1 D-G$, available at www.jneurosci.org as supplemental material). The WGA-labeled neurons in spinal rats were similar in location, size, and shape to those found in intact rats (Fig. 4A-C). We found more WGA-positive somata in the red nucleus, locus coeruleus, vestibular nucleus, and raphe nucleus but not in the reticular formation of OEG- than media-injected rats (Table 1, Fig. $4 D$ ). There were no WGA-positive somata in the primary motor cortex of any spinal rat (supplemental Fig. $1 B$, available at www. jneurosci.org as supplemental material). We detected more WGA-positive somata in laminae VII, VIII, and X of the cervical enlargement in OEG- than media-injected rats (Fig. 4D). These retrogradely labeled cell bodies were round or oval in shape and 20-30 $\mu \mathrm{m}$ in diameter with multipolar processes, features typical of long propriospinal neurons that contact lumbar somatic motor neurons (Menétrey et al., 1985).

Next we asked whether the number of retrogradely labeled somata in media-injected controls was consistent with spontaneous axon regeneration or nonspecific uptake of the tracer. To address this issue, we injected WGA-HRP into three mediainjected spinal rats 1 month after transection as an additional control. We detected WGA-labeled somata in all three media rats 


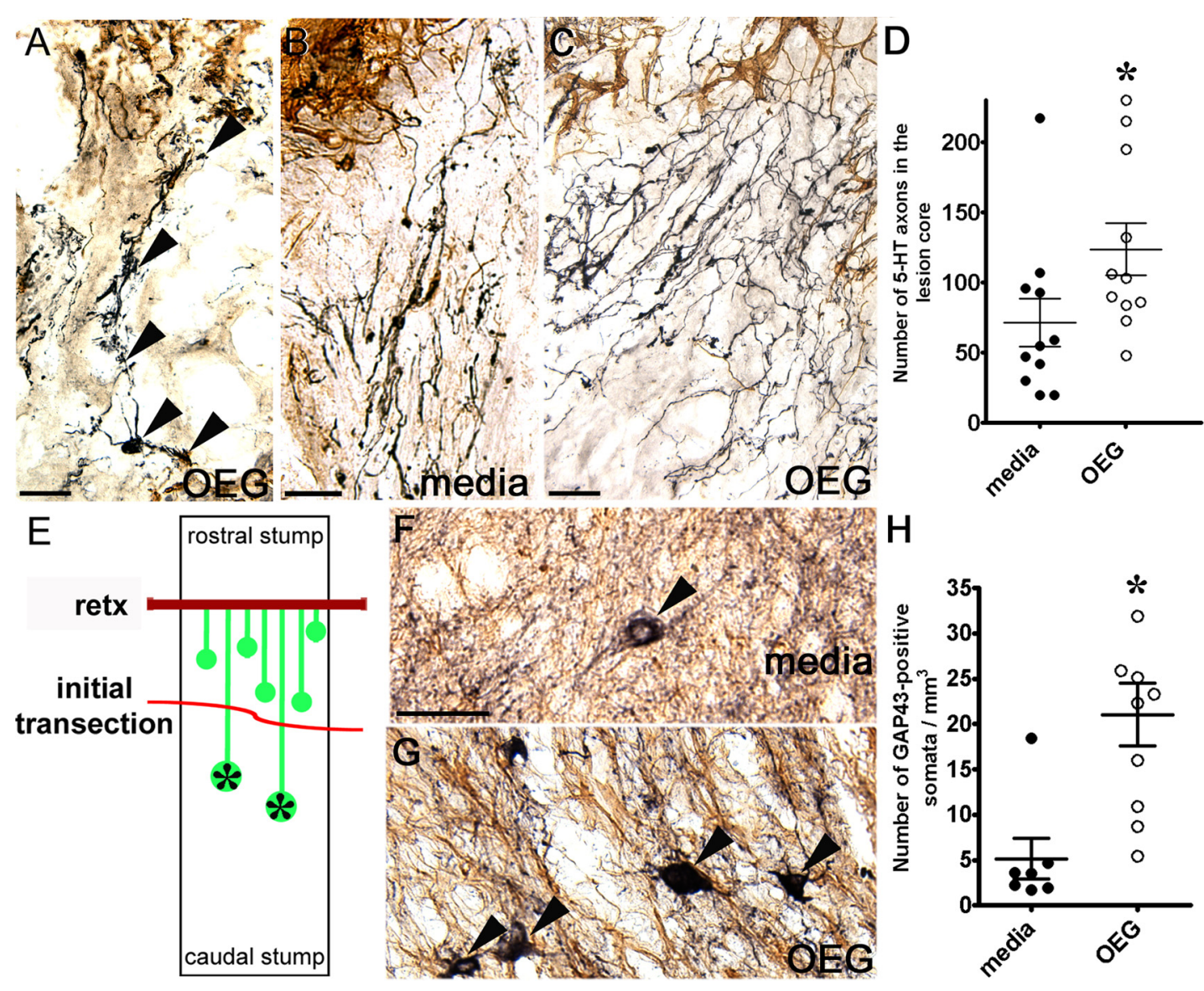

Figure 5. Axons regenerate in $0 \mathrm{EG}$-injected rats. $A, A$ - $-\mathrm{HT}$-labeled axon (black, arrowheads) projects into and spans the transection site in an $0 \mathrm{EG}$-injected rat. Rostral and caudal GFAP-positive borders (brown) are at the top and bottom of the image. B, C, Many 5-HT axons (black) cross the rostral GFAP-positive border (brown, at the top) in both media-injected $(\boldsymbol{B})$ and 0 EG-injected $(\boldsymbol{C})$ rats. $\boldsymbol{D}$, More 5 -HT axons are found within the lesion core of 0 EG- than media-injected rats $\left({ }^{*} p=0.02\right)$. $\boldsymbol{E}$, Diagram of the injury site of the retransected spinal cord. Only GAP43 expression in somata within the caudal stump (*) after retransection suggests axon regeneration of ascending axons. $F, G$, GAP43-positive cell bodies (black) in media $(\boldsymbol{F})$ and OEG (G) GFAP-positive caudal stumps (brown). $\boldsymbol{H}$, More GAP43-positive somata are detected in the caudal stump of 0EG-than media-injected rats $\left({ }^{*} p<0.01\right) . S c a l e$ bars, $50 \mu \mathrm{m}$. Data are mean \pm SEM.

maintained for 1 month that presumably would have no axon regeneration (Table 1, Fig. 4D). Moreover, the average number of labeled cells in the brainstem or cervical spinal cord did not differ significantly between media rats after 1 or 8 months post-injury. These results suggest a consistent level of spurious WGA-labeled somata in spinal rats rather than spontaneous regeneration (Fig. 4D). Overall, detection of more retrogradely labeled cells in the brainstem (excluding the reticular formation) and spinal cord of OEG- than media-injected long-term spinal rats is consistent with our behavioral and electrophysiological evidence that OEG transplantation promoted axon regeneration across the transection.

\section{Raphespinal regeneration}

To test whether OEG transplantation promotes raphespinal regeneration, we examined the presence of serotonergic axons spanning the lesion. We found examples of axons that projected across both GFAP borders and the GFAP-negative lesion core only in OEG-injected rats (Fig. 5A). We also observed 5-HT axons that sprouted within the lesion core in both media- and OEG-injected rats (Fig. $5 B, C$ ), with more found in OEG- than media-injected rats (Fig. 5D). To determine whether these 5-HT axons in the lesion core originated from the raphe nucleus or spinal cord interneurons (Newton and Hamill, 1988; Takeoka et al., 2009), we examined the original lesion core from retransected spinal rats and found few 5-HT axons. This finding suggests that the 5-HT axons that sprouted into the lesion core originated primarily from raphespinal neurons rather than intraspinal 5-HT neurons. We did not examine the 5-HT axons in the caudal stump because they could originate from the rare serotonergic spinal neurons and do not necessarily represent raphespinal regeneration (Takeoka et al., 2009).

\section{Ascending axon regeneration}

GAP43 is transiently expressed in somata and growing axons of most neurons during development (Jacobson et al., 1986; Goslin et al., 1990). After axotomy, adult neurons, such as retinal ganglion cells, dorsal root ganglion, and spinal neurons, transiently express GAP43 in their somata (Doster et al., 1991; Schreyer and Skene, 1991; Siebert et al., 2010). Because GAP43 is a marker of recent axotomy, we hypothesized that any ascending axons that regenerated across the original transection would transiently upregulate GAP43 in their cell bodies after retransection $0.5 \mathrm{~cm}$ rostral to the initial site (diagram in Fig. $5 E$ ). First, we examined spinal rats that did not receive a retransection and found no labeled somata but numerous GAP43-positive axons within the lesion core, fibers associated with the meninges and penetrating blood vessels, and labeled axons within the dorsal and ventral roots (data not shown), in a pattern similar to peripherally derived noradrenergic axons (Takeoka et al., 2010). After retransection, axotomized GAP43-positive somata filled the rostral stump 
between the initial and retransection sites in both media and OEG groups (diagram in Fig. 5E). In contrast, sparse GAP43labeled somata occupied the caudal stump of the retransected cords, primarily in lamina $\mathrm{V}$ with a few cells in lamina $\mathrm{X}$ (Fig. $5 F, G)$. These GAP43-labeled somata caudal to the initial transection likely represent neurons with axons that had regenerated past the original lesion and far enough rostrally to be axotomized by the retransection. This interpretation of upregulated somatic GAP43 is only valid in the caudal stump of spinal cord injury studies that use an initial complete transection, followed by a lengthy period for axon regeneration to occur, a complete spinal cord retransection rostral to the original injury, and then perfusions performed within $14 \mathrm{~d}$ after retransection. We quantified GAP43-labeled cell bodies in the caudal stump and found more GAP43immunopositive somata in OEG than media groups (Fig. 5H). These results suggest that OEG implantation promotes regeneration of ascending axons and that a limited amount of spontaneous regeneration may occur in longterm, media-injected rats.

\section{OEG preserve tissue and neurons surrounding the lesion}

We measured the volume of the GFAP-

negative lesion core and associated cavitations to determine whether OEG attenuate tissue degeneration after the injury. The average volume of the injury site was larger in media- than OEGinjected rats (Fig. 6A,B), results consistent with our previous studies (Kubasak et al., 2008; Muñoz-Quiles et al., 2009). We identified the rostral and caudal stumps with anti-GFAP and spinal cord neurons with anti-NeuN to evaluate the extent of injury-induced neuronal degeneration (Fig. 6C). We found NeuN-labeled cell bodies immediately adjacent to the GFAPnegative lesion core more often in OEG-injected (Fig. 6D) than media-injected (Fig. 6C) spinal cords. The distance between the most proximal NeuN-labeled neuron and the GFAP-negative lesion core was shorter in the rostral than in the caudal stump of all spinal rats (media: rostral, $0.67 \pm 0.06 \mathrm{~cm}$ and caudal, $1.31 \pm 0.11$ $\mathrm{cm}$; OEG: rostral, $0.25 \pm 0.07 \mathrm{~cm}$ and caudal, $0.48 \pm 0.06 \mathrm{~cm} ; p<$ $0.05)$, a result that indicates that more neurons in the rostral stump were preserved than in the caudal stump. Furthermore, both the average GFAP-positive non-neuronal zone (Fig. 6E) and the total distance between neurons located in the rostral and caudal stumps (Fig. 6F) were shorter in OEG than media groups. These results suggest that OEG transplantation promotes neuronal survival after a complete transection, and, consequently, in combination with a smaller lesion volume, regenerating axons would have a shorter distance to project to a neuronal target on the opposite side of the transection in OEG- than media-injected rats.

\section{p75-NGFR-positive OEG survive 8 months} after transplantation

OEG were prelabeled with Hoechst (Ramón-Cueto et al., 2000), and, 8 months later, we used anti-p75-NGFR to identify immunolabeled OEG with Hoechst-labeled nuclei in and near the transection (Pearse et al., 2007; Lankford et al., 2008). We detected a number of p75-NGFR- and Hoechst-labeled cells within the spinal stumps (Fig. $7 A, B$ ) and the lesion core (Fig. $7 C)$. These putative OEG usually are clustered, frequently aligned with each other, and form tubular structures (Fig. $7 \mathrm{~B}, \mathrm{C}$ ) as reported after transplantation in vivo (Sasaki et al., 2004). OEG also are characterized by smooth oval nuclei (Field et al., 2003; Smithson et al., 2010), a feature that distinguishes them from macrophages or activated microglia (Nguyen et al., 1994; Raivich et al., 1998). In addition to OEG, endogenous Schwann cells that migrate into the core of the injury also express p75-NGFR and thus are not distinguishable from OEG. However, colocalized p75-NGFR/Hoechst-labeled cells in the spinal cord stumps are likely to be OEG because Schwann cells do not integrate into spinal cord areas bordered by an astrocytic scar (Lakatos et al., 2000; Raisman and Li, 2007). Other Hoechst-labeled nuclei without p75-NGFR expression likely represent the portion of transplanted OEG that downregulate p75-NGFR expression or a redistribution of Hoechst dye to host cells (Iwashita et al., 2000). We also determined that ED1-positive macrophages rarely contained Hoechst-labeled nuclei in OEG-injected rats (Fig. 7D) and that the distribution of ED1-positive macrophages around the lesion core was similar in media- and OEG-injected spinal cords at 8 months after transection. Although Hoechst labeling alone cannot determine the full extent of OEG survival, doublelabeled p75-NGFR and Hoechst profiles suggest that OEG are present 8 months after implantation. 

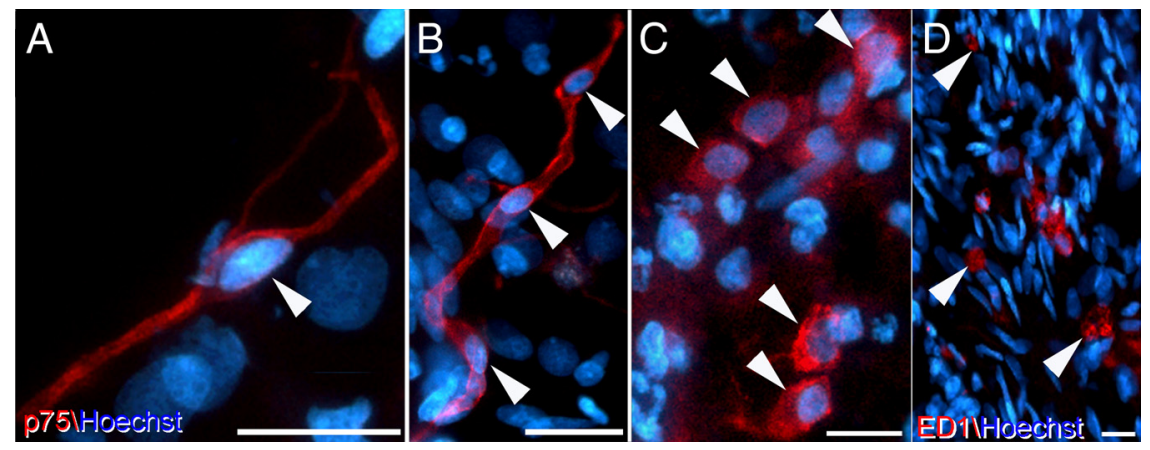

Figure 7. OEG identified with anti-p75-NGFR and ED1-labeled macrophages are detected at 8 months after transection. $\boldsymbol{A}, \boldsymbol{B}$ Hoechst-labeled nuclei (blue) are found within p75-NGFR-positive cells (red) and suggest the presence of transplanted OEG (white arrowheads) in the rostral $(\boldsymbol{A})$ and caudal $(\boldsymbol{B})$ spinal cord stumps. $\boldsymbol{C}$, Hoechst-labeled nuclei (blue; white arrowheads) within p75-NGFR-positive cells (red) in the lesion core are likely OEG but Schwann cells within the transection also express p75-NGFR. $\boldsymbol{D}$, Most ED1-labeled macrophages (red; white arrowheads) do not colocalize with Hoechst-positive nuclei (blue). Scale bars, $25 \mu \mathrm{m}$.

\section{8 months post-transection}

\section{re-transection}

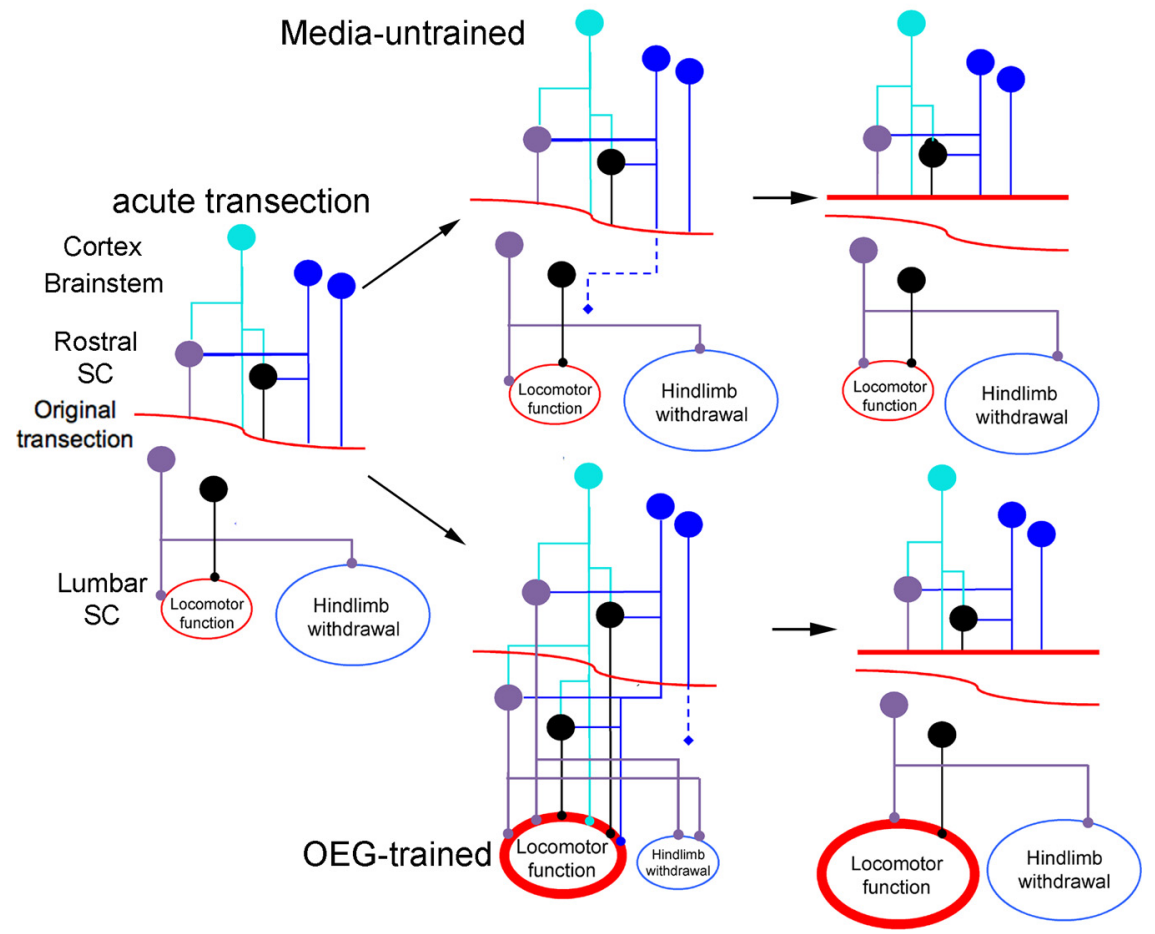

Figure 8. Summary diagram of how axon regeneration and caudal stump reorganization might contribute to sensorimotor function. Left, Immediately after a complete transection (approximately T9, curved red line), the lumbar spinal cord (SC) is isolated from supraspinal and rostral spinal connections. Middle row, At 8 months after lesion, media-untrained rats have little evidence of locomotor recovery (small oval, thin red outline) and hypersensitive hindlimb withdrawal (large oval, thin blue outline). In OEG-trained rats, direct or indirect connections, i.e., connections including long and short propriospinal neurons, are formed across the transection that activate or suppress lumbar somatic motor neurons. Functionally, $0 \mathrm{EG}$-trained rats have improved locomotor circuits (small oval, thick red outline) and less sensitive hindlimb withdrawal (small oval, thin blue outline). Right, Although retransection (approximately T6, straight red line) does not alter locomotor and hindlimb withdrawal functions of mediauntrained rats, 0EG-trained rats step better (large oval, thick red outline) and become hypersensitive to mechanical stimulation (large oval, thin blue outline). Retransection removes the suppression of the sensorimotor function. Corticospinal neurons are light blue, brainstem projection neurons are dark blue, and spinal interneurons, i.e., long and short propriospinal neurons, are light purple and black and represent suppression or facilitation of motor functions, respectively. Axons drawn in dotted lines indicate only anatomical evidence of regeneration. The size of spinal circuits represents the relative contribution to the functional outcome, and changes in thickness of outlines for locomotor function represent the extent of intraspinal reorganization.

\section{Discussion}

OEG facilitated regeneration across the lesion and reorganization of neural circuits in the caudal stump. Behavioral and electro- physiological data after complete spinal cord retransection experiments 8 months after the initial lesion convincingly demonstrated that the regenerating axons in OEG-injected rats were functional. After retransection, no MEPs remained, the decreased hypersensitivity to mechanical stimulation was reversed, and some OEG-injected rats dramatically improved their locomotor performance. OEG transplantation combined with step training facilitated the reorganization of lumbosacral circuits that contributed to improved stepping with quipazine and to the weight-supporting ability of adult spinal rats. OEG transplantation also preserved neurons and reduced the volume of the lesion core, changes that would facilitate axon regeneration across the transection. These changes reflect the combination of spinal circuit reorganization and axon regeneration that together suppressed or facilitated sensorimotor function (Fig. 8).

\section{Evidence of caudal stump reorganization in the recovery of motor function}

Our previous study (Kubasak et al., 2008) reported that step training alone did not improve locomotor function of mediainjected adult rats but OEG transplantation alone improved hindlimb locomotion, findings confirmed by the current results. Kubasak et al. (2008) also showed that OEG-trained rats improved their stepping ability over time, whereas in the present study, improvement of plantar stepping plateaued early. This early improvement likely represents reorganization within the caudal stump because there was no electrophysiological evidence of regeneration at 1 month after transection. Improved plantar stepping in OEG groups and longer stance and step trajectories in OEG-trained compared with OEG-untrained rats after retransection suggest that OEG transplantation alone strengthened, and long-term training further enhanced, function within the locomotor networks. One factor that could facilitate locomotion is the increased frequency of serotonergic and noradrenergic varicosities apposing the motor-associated cholinergic neurons in OEG-injected rats (Takeoka et al., 2009, 2010). Additionally, OEG and step training improved locomotor performance after pharmacological activation of $5-\mathrm{HT}_{2 \mathrm{~A}}$ receptors. Because retransection did not alter the improved plantar stepping ability of media- and OEG-trained rats with quipazine, the improvement was likely attributable to changes within the caudal stump rather than axonal regeneration. 


\section{Evidence of axon regeneration across the transection}

Spinal cord retransections provided critical evidence that OEG transplantation facilitated functionally relevant axon regeneration. Surprisingly, several OEG-injected rats that never plantar stepped during the 7 monthly kinematics tests dramatically improved their stepping performance after retransection, a result that suggests that regenerated axons suppressed stepping (Fig. 8). Both facilitation and suppression of the spinal circuitry are important in the control of intact locomotion (Bonnot et al., 1998; Iglesias et al., 2008). It is unclear the extent to which the regenerated axons are functional, i.e., the net effect is that they are "inhibitory" to locomotor circuits in the classical neurophysiological definition, or dysfunctional in the sense that they interfere with hindlimb stepping functions. Nonetheless, axon regeneration appears to have a net suppressive effect on the locomotor networks and the injury-induced hypersensitive hindlimb withdrawal in this study. These results emphasize that, even when axon regeneration is identified electrophysiologically and anatomically, behavioral consequences may be unpredictable.

Our electrophysiological results indicate that axons regenerate across the transection and form functional connections in OEG-injected rats, but the process occurred slowly and connections were less stable than those in intact rats. By 4 months after transection, we found reconnections with long latencies, features consistent with polysynaptic and/or slow electrical conduction. We rarely, and only at 7 months, detected MEPs with latencies similar to those of intact rats. The small amplitudes of most MEPs imply that relatively few connections were reestablished. Although intact rats had a 100\% frequency of response to transcranial stimulation, we saw inconsistent responses in OEG-injected rats, reflecting weak connections established by regenerating axons.

Combined with electrophysiological data, retrograde tracing results suggest that the re-established projections to somatic motor neurons were mainly polysynaptic. For example, two OEG-injected rats that responded to cortical stimulation were injected with the retrograde tracer, but neither had WGA-labeled somata in the motor cortex. Interpretations consistent with these data are that corticospinal axons sprouted in the rostral stump and contacted interneurons that then crossed the transection or that corticospinal axons crossed the transection site and contacted an interneuron that eventually projected to somatic motor neurons (Fig. 8). Similarly, the brainstem nuclei re-established connections that were predominantly polysynaptic, and this may explain why some OEG-injected rats had relatively few retrogradely labeled cells in the brainstem although MEPs were recorded in their hindlimb muscles. Alternatively, some regenerated axons could be electrically silent but able to transport the tracer. Perhaps some regenerating axons establish nonfunctional or aberrant connections that then are later eliminated (Bareyre et al., 2004; Calancie et al., 2005), recapitulating the process of synapse elimination during development. Additional evidence consistent with axon regeneration in OEG-injected rats includes raphespinal axons that spanned the transection and upregulation of GAP43 in somata that likely represents a response to axotomy after retransection. GAP43-positive somata in the caudal stump of OEG-injected rats were located primarily in lamina $\mathrm{V}$, which contains many ascending sensory neurons (Baker and Giesler, 1984; Menétrey and Basbaum, 1987; Villanueva et al., 1991; Ramón-Cueto et al., 1998). Detailed sensory testing was not performed in this study, and therefore it is unclear whether these axons have functional consequences.

Finally, there is an inconsistency between the electrophysiological and anatomical results in long-term media-injected rats. Although some spurious labeling occurred after WGA-HRP injections, we detected extensive WGA-labeled somata in the red nucleus of two media rats maintained for 8 months after transection but not in 1 month media controls. Chronic media rats also had several GAP43-positive somata in the caudal stump after retransection. Because we electrophysiologically and anatomically confirmed that transections were complete, these results leave open the possibility that limited spontaneous axon regeneration may occur in long-term spinal rats as suggested by Muñoz-Quiles et al. (2009). In the present study, however, there was no evidence that spontaneous regeneration contributed to functional changes. Importantly, the combination of retrograde tracer and retransection data caution against the overinterpretation of anatomical evidence of regeneration and demonstrate the value of a retransection experiment to determine whether regenerating axons are functional.

\section{Promotion of axon regeneration and beyond}

The current study raises an important question of how OEG promote axon regeneration after injury. Olfactory bulb-derived OEG can reduce inhibitory molecules (García-Alías et al., 2004), alter immune and inflammatory responses (López-Vales et al., 2004; Chuah et al., 2010), and integrate into the CNS environment as they intermingle with astrocytes both in vitro and in vivo (Franklin et al., 1996; Imaizumi et al., 1998; Lakatos et al., 2000, 2003; Raisman and Li, 2007). The present results do not provide additional insight into the possible mechanisms.

How axon regeneration and the reorganization of spinal neural circuitry might contribute to the improvement in motor function is complex (Fig. 8). Having now established that mature regenerating axons can form functionally relevant connections across a complete spinal cord transection, an important future challenge is to optimize the extent and balance of axon regeneration, maximize functionally useful axon-target reconnections, and identify strategies to further facilitate functional efficacy.

\section{References}

Baker ML, Giesler GJ Jr (1984) Anatomical studies of the spinocervical tract of the rat. Somatosens Res 2:1-18.

Bareyre FM, Kerschensteiner M, Raineteau O, Mettenleiter TC, Weinmann O, Schwab ME (2004) The injured spinal cord spontaneously forms a new intraspinal circuit in adult rats. Nat Neurosci 7:269-277.

Bonnot A, Corio M, Bouc AM, Viala D (1998) Involvement of AMPA receptors in posterior locomotor activity in the rabbit: an in vivo study. J Physiol Paris 92:5-15.

Cai LL, Fong AJ, Otoshi CK, Liang Y, Burdick JW, Roy RR, Edgerton VR (2006) Implications of assist-as-needed robotic step training after a complete spinal cord injury on intrinsic strategies of motor learning. J Neurosci 26:10564-10568.

Calancie B, Alexeeva N, Broton JG, Molano MR (2005) Interlimb reflex activity after spinal cord injury in man: strengthening response patterns are consistent with ongoing synaptic plasticity. Clin Neurophysiol 116:75-86.

Chandler CE, Parsons LM, Hosang M, Shooter EM (1984) A monoclonal antibody modulates the interaction of nerve growth factor with PC12 cells. J Biol Chem 259:6882-6889.

Chaplan SR, Bach FW, Pogrel JW, Chung JM, Yaksh TL (1994) Quantitative assessment of tactile allodynia in the rat paw. J Neurosci Methods 53:55-63.

Chuah MI, Hale DM, West AK (2010) Interaction of olfactory ensheathing cells with other cell types in vitro and after transplantation: glial scars and inflammation. Exp Neurol. Advance online publication. Retrieved January 24, 2011. doi:10.1016/j.expneurol.2010.08.012. 
Côté MP, Gossard JP (2003) Task-dependent presynaptic inhibition. J Neurosci 23:1886-1893.

Côté MP, Ménard A, Gossard JP (2003) Spinal cats on the treadmill: changes in load pathways. J Neurosci 23:2789-2796.

Courtine G, Song B, Roy RR, Zhong H, Herrmann JE, Ao Y, Qi J, Edgerton VR, Sofroniew MV (2008) Recovery of supraspinal control of stepping via indirect propriospinal relay connections after spinal cord injury. Nat Med 14:69-74.

Courtine G, Gerasimenko Y, van den Brand R, Yew A, Musienko P, Zhong H, Song B, Ao Y, Ichiyama RM, Lavrov I, Roy RR, Sofroniew MV, Edgerton VR (2009) Transformation of nonfunctional spinal circuits into functional states after the loss of brain input. Nat Neurosci 12:1333-1342.

de Leon RD, Tamaki H, Hodgson JA, Roy RR, Edgerton VR (1999) Hindlimb locomotor and postural training modulates glycinergic inhibition in the spinal cord of the adult spinal cat. J Neurophysiol 82:359-369.

Doster SK, Lozano AM, Aguayo AJ, Willard MB (1991) Expression of the growth-associated protein GAP-43 in adult rat retinal ganglion cells following axon injury. Neuron 6:635-647.

Edgerton VR, de Leon RD, Tillakaratne N, Recktenwald MR, Hodgson JA, Roy RR (1997) Use-dependent plasticity in spinal stepping and standing. Adv Neurol 72:233-247.

Edgerton VR, Tillakaratne NJ, Bigbee AJ, de Leon RD, Roy RR (2004) Plasticity of the spinal neural circuitry after injury. Annu Rev Neurosci $27: 145-167$.

Efron B, Tibshirani R (1991) Statistical data analysis in the computer age. Science 253:390-395.

Field P, Li Y, Raisman F (2003) Ensheathment of the olfactory nerves in the adult rat. J Neurocytol 32:317-324.

Fong AJ, Cai LL, Otoshi CK, Reinkensmeyer DJ, Burdick JW, Roy RR, Edgerton VR (2005) Spinal cord-transected mice learn to step in response to quipazine treatment and robotic training. J Neurosci 25:11738-11747.

Fouad K, Schnell L, Bunge MB, Schwab ME, Liebscher T, Pearse DD (2005) Combining Schwann cell bridges and olfactory-ensheathing glia grafts with chondroitinase promotes locomotor recovery after complete transection of the spinal cord. J Neurosci 25:1169-1178.

Franklin RJ, Gilson JM, Franceschini IA, Barnett SC (1996) Schwann celllike myelination following transplantation of an olfactory bulbensheathing cell line into areas of demyelination in the adult CNS. Glia $17: 217-224$

Franssen EH, de Bree FM, Verhaagen J (2007) Olfactory ensheathing glia: their contribution to primary olfactory nervous system regeneration and their regenerative potential following transplantation into the injured spinal cord. Brain Res Rev 56:236-258.

García-Alías G, Verdú E, Forés J, López-Vales R, Navarro X (2003) Functional and electrophysiological characterization of photochemical graded spinal cord injury in the rat. J Neurotrauma 20:501-510.

García-Alías G, López-Vales R, Forés J, Navarro X, Verdú E (2004) Acute transplantation of olfactory ensheathing cells or Schwann cells promotes recovery after spinal cord injury in the rat. J Neurosci Res 75:632-641.

Gerasimenko YP, Ichiyama RM, Lavrov IA, Courtine G, Cai L, Zhong H, Roy RR, Edgerton VR (2007) Epidural spinal cord stimulation plus quipazine administration enable stepping in complete spinal adult rats. J Neurophysiol 98:2525-2536.

Goslin K, Schreyer DJ, Skene JH, Banker G (1990) Changes in the distribution of GAP-43 during the development of neuronal polarity. J Neurosci 10:588-602.

Gruner JA, Wade CK, Menna G, Stokes BT (1993) Myoelectric evoked potentials versus locomotor recovery in chronic spinal cord injured rats. J Neurotrauma 10:327-347.

Ichiyama RM, Gerasimenko YP, Zhong H, Roy RR, Edgerton VR (2005) Hindlimb stepping movements in complete spinal rats induced by epidural spinal cord stimulation. Neurosci Lett 383:339-344.

Ichiyama RM, Courtine G, Gerasimenko YP, Yang GJ, van den Brand R, Lavrov IA, Zhong H, Roy RR, Edgerton VR (2008) Step training reinforces specific spinal locomotor circuitry in adult spinal rats. J Neurosci 28:7370-7375.

Ichiyama R, Potuzak M, Balak M, Kalderon N, Edgerton VR (2009) Enhanced motor function by training in spinal cord contused rats following radiation therapy. PLoS One 4:e6862.

Iglesias C, Nielsen JB, Marchand-Pauvert V (2008) Corticospinal inhibition of transmission in propriospinal-like neurones during human walking. Eur J Neurosci 28:1351-1361.
Imaizumi T, Lankford KL, Waxman SG, Greer CA, Kocsis JD (1998) Transplanted olfactory ensheathing cells remyelinate and enhance axonal conduction in the demyelinated dorsal columns of the rat spinal cord. J Neurosci 18:6176-6185.

Iwashita Y, Crang AJ, Blakemore WF (2000) Redistribution of bisbenzimide Hoechst 33342 from transplanted cells to host cells. Neuroreport 11:1013-1016.

Jacobson RD, Virág I, Skene JH (1986) A protein associated with axon growth, GAP-43, is widely distributed and developmentally regulated in rat CNS. J Neurosci 6:1843-1855.

Kubasak MD, Jindrich DL, Zhong H, Takeoka A, McFarland KC, MuñozQuiles C, Roy RR, Edgerton VR, Ramón-Cueto A, Phelps PE (2008) OEG implantation and step training enhance hindlimb-stepping ability in adult spinal transected rats. Brain 131:264-276.

Lakatos A, Franklin RJ, Barnett SC (2000) Olfactory ensheathing cells and Schwann cells differ in their in vitro interactions with astrocytes. Glia 32:214-225.

Lakatos A, Barnett SC, Franklin RJ (2003) Olfactory ensheathing cells induce less host astrocyte response and chondroitin sulphate proteoglycan expression than Schwann cells following transplantation into adult CNS white matter. Exp Neurol 184:237-246.

Lankford KL, Sasaki M, Radtke C, Kocsis JD (2008) Olfactory ensheathing cells exhibit unique migratory, phagocytic, and myelinating properties in the X-irradiated spinal cord not shared by Schwann cells. Glia $56: 1664-1678$.

Li Y, Sauvé Y, Li D, Lund RD, Raisman G (2003) Transplanted olfactory ensheathing cells promote regeneration of cut adult rat optic nerve axons. J Neurosci 23:7783-7788.

Li Y, Yamamoto M, Raisman G, Choi D, Carlstedt T (2007) An experimental model of ventral root repair showing the beneficial effect of transplanting olfactory ensheathing cells. Neurosurgery 60:734-740; discussion $740-741$.

López-Vales R, García-Alías G, Forés J, Vela JM, Navarro X, Verdú E (2004) Transplanted olfactory ensheathing cells modulate the inflammatory response in the injured spinal cord. Neuron Glia Biol 1:201-209.

López-Vales R, Forés J, Verdú E, Navarro X (2006) Acute and delayed transplantation of olfactory ensheathing cells promote partial recovery after complete transection of the spinal cord. Neurobiol Dis 21:57-68.

Magladery JW, Teasdall RD, Park AM, Languth HW (1952) Electrophysiological studies of reflex activity in patients with lesions of the nervous system. I. A comparison of spinal motoneurone excitability following afferent nerve volleys in normal persons and patients with upper motor neurone lesions. Bull Johns Hopkins Hosp 91:219-244; passim.

Menétrey D, Basbaum AI (1987) Spinal and trigeminal projections to the nucleus of the solitary tract: a possible substrate for somatovisceral and viscerovisceral reflex activation. J Comp Neurol 255:439-450.

Menétrey D, de Pommery J, Roudier F (1985) Propriospinal fibers reaching the lumbar enlargement in the rat. Neurosci Lett 58:257-261.

Muñoz-Quiles C, Santos-Benito FF, Llamusí MB, Ramón-Cueto A (2009) Chronic spinal injury repair by olfactory bulb ensheathing glia and feasibility for autologous therapy. J Neuropathol Exp Neurol 68:1294-1308.

Newton BW, Hamill RW (1988) The morphology and distribution of rat serotonergic intraspinal neurons: an immunohistochemical study. Brain Res Bull 20:349-360.

Nguyen KB, McCombe PA, Pender MP (1994) Macrophage apoptosis in the central nervous system in experimental autoimmune encephalomyelitis. J Autoimmum 7:145-152.

Pearse DD, Sanchez AR, Pereira FC, Andrade CM, Puzis R, Pressman Y, Golden K, Kifay BM, Blits B, Wood PM, Bunge MB (2007) Transplantation of Schwann cells and/or olfactory ensheathing glia into the contused spinal cord: survival, migration, axon association, and fundamental recovery. Glia 55:976-1000.

Protas DT, Brown BG, Jung R, Jindrich DL (2008) Selective neurotransmitter blockers affect motor evoked potentials in anesthetized rats. Soc Neurosci Abstr 34:74.7.

Raisman G, Li Y (2007) Repair of neural pathways by olfactory ensheathing cells. Nat Rev Neurosci 8:312-319.

Raivich G, Jones LL, Kloss CU, Werner A, Neumann H, Kreutzberg GW (1998) Immune surveillance in the injured nervous system: T-lymphocytes invade the axotomized mouse facial motor nucleus and aggregate around sites of neuronal degeneration. J Neurosci 18:5804-5816. 
Ramón-Cueto A, Plant GW, Avila J, Bunge MB (1998) Long-distance axonal regeneration in the transected adult rat spinal cord is promoted by olfactory ensheathing glia transplants. J Neurosci 18:3803-3815.

Ramón-Cueto A, Cordero MI, Santos-Benito FF, Avila J (2000) Functional recovery of paraplegic rats and motor axon regeneration in their spinal cords by olfactory ensheathing glia. Neuron 25:425-435.

Reese NB, Skinner RD, Mitchell D, Yates C, Barnes CN, Kiser TS, Garcia-Rill E (2006) Restoration of frequency-dependent depression of the $\mathrm{H}$-reflex by passive exercise in spinal rats. Spinal Cord 44:28-34.

Rossignol S, Giroux N, Chau C, Marcoux J, Brustein E, Reader TA (2001) Pharmacological aids to locomotor training after spinal injury in the cat. J Physiol 533:65-74.

Sasaki M, Lankford KL, Zemedkun M, Kocsis JD (2004) Identified olfactory ensheating cells transplanted into the transected dorsal funiculus bridge the lesion and form myelin. J Neurosci 24:8485-8493.

Schreyer DJ, Skene JH (1991) Fate of GAP-43 in ascending spinal axons of DRG neurons after peripheral nerve injury: delayed accumulation and correlation with regenerative potential. J Neurosci 11:3738-3751.

Siebert JR, Middelton FA, Stelzner DJ (2010) Intrinsic response of thoracic propriospinal neurons to axotomy. BMC Neuroscience 11:69.

Smithson LJ, Kawaja MD (2010) Microglial/macrophage cells in mammalian olfactory nerve fascicles. J Neurosci Res 88:858-865.

Takeoka A, Kubasak MD, Zhong H, Roy RR, Phelps PE (2009) Serotonergic innervation of the caudal spinal stump in rats after complete spinal transection: effect of olfactory ensheathing glia. J Comp Neurol 515:664-676.

Takeoka A, Kubasak MD, Zhong H, Kaplan J, Roy RR, Phelps PE (2010) Noradrenergic innervation of the rat spinal cord caudal to a complete spinal cord transection: effects of olfactory ensheathing glia. Exp Neurol 222:59-69.

Tillakaratne NJ, Mouria M, Ziv NB, Roy RR, Edgerton VR, Tobin AJ (2000) Increased expression of glutamate decarboxylase (GAD67) in feline lumbar spinal cord after complete thoracic spinal cord transection. J Neurosci Res 60:219-230.

Tillakaratne NJ, de Leon RD, Hoang TX, Roy RR, Edgerton VR, Tobin AJ (2002) Use-dependent modulation of inhibitory capacity in the feline lumbar spinal cord. J Neurosci 22:3130-3143.

Timoszyk WK, De Leon RD, London N, Roy RR, Edgerton VR, Reinkensmeyer DJ (2002) The rat lumbosacral spinal cord adapts to robotic loading applied during stance. J Neurophysiol 88:3108-3117.

Villanueva L, de Pommery J, Menétrey D, Le Bars D (1991) Spinal afferent projections to subnucleus reticularis dorsalis in the rat. Neurosci Lett 134:98-102.

Zemlan FP, Kow LM, Pfaff DW (1984) Analgesia after lesions of nucleus reticularis magnocellularis: differential effect on supraspinal versus spinal pain reflexes. Pain 18:221-237. 